\title{
Identification, sequencing and comparative analysis of pBp15.S plasmid from the newly described entomopathogen Bacillus pumilus 15.1
}

\author{
Diana C. Garcia-Ramon a , Maria Jose Luque-Navas a , C. Alfonso Molina ${ }^{\text {b }}$, Coral del Val ${ }^{\text {, }}$ \\ Antonio Osuna ${ }^{\text {a }}$, Susana Vilchez ${ }^{\text {a,d,* }}$ \\ a Institute of Biotechnology, Campus Fuentenueva s/n, University of Granada, 18071 Granada, Spain \\ ${ }^{\mathrm{b}}$ International Center for Zoonoses (CIZ), Faculty of Veterinary Medicine and Zootechnic, Central University of Ecuador, PO Box.17-03-100, Quito, Ecuador \\ c Department of Computer Science and Artificial Intelligence, Campus Fuentenueva s/n, University of Granada, 18071 Granada, Spain \\ d Department of Biochemistry and Molecular Biology I, Campus Fuentenueva s/n, University of Granada, 18071 Granada, Spain
}

\section{A R T I C L E I N F O}

\section{Article history:}

Received 30 July 2015

Received in revised form 21 September 2015

Accepted 23 September 2015

Available online 28 September 2015

\section{Keywords:}

Bacillus pumilus plasmid

Virulence factors

Rep

RapA

RapAB

Small rolling circle plasmid

\begin{abstract}
A B S T R A C T
The Bacillus pumilus 15.1 strain, a recently described entomopathogenic strain active against Ceratitis capitata, contains at least two extrachromosomal elements, pBp15.1S and pBp15.1B. Given that $B$. pumilus is not a typical entomopathogenic bacterium, the acquisition of this extrachromosomal DNA may explain why B. pumilus 15.1 is toxic to an insect. One of the plasmids present in the strain, the pBp15.1S plasmid, was sub-cloned, sequenced and analyzed using bioinformatics to identify any potential virulence factor. The $\mathrm{pBp} 15.1 \mathrm{~S}$ plasmid was found to be 7785 bp in size with a GC content of $35.7 \%$ and 11 putative ORFs. A replication module typical of a small rolling circle plasmid and a sensing and regulatory system specific for plasmids was found in pBp15.1S. Additionally, we demonstrated the existence of ssDNA in plasmid preparations suggesting that $\mathrm{pBp} 15.1 \mathrm{~S}$ replicates by the small rolling circle mechanism. A gene cluster present in plasmid pPZZ84 from a distantly isolated B. pumilus strain was also present in pBp15.1S. The plasmid copy number of pBp15.1S in exponentially growing B. pumilus cells was determined to be 33 copies per chromosome. After an extensive plasmid characterization, no known virulence factor was found so a search in the other extrachromosomal elements of the bacteria is needed.
\end{abstract}

(c) 2015 Elsevier Inc. All rights reserved.

\section{Introduction}

Extrachromosomal DNA is common in the bacteria kingdom. Usually found as covalently closed circular DNA (CCC DNA) or plasmids, it endows the bacteria with additional biochemical capabilities different from those coded by the chromosome, and sometimes with very special features. Bacterial plasmids,

\footnotetext{
* Corresponding author at: Department of Biochemistry and Molecular Biology I, University of Granada, Campus Universitario Fuentenueva, 18071 Granada, Spain.

E-mail addresses: dianacg85@yahoo.com (D.C. Garcia-Ramon), mjlunavas@correo.ugr.es (M.J. Luque-Navas), alf.molina7@gmail.com (C.A. Molina), delval@decsai.ugr.es (C. del Val), aosuna@ugr.es (A. Osuna), svt@ugr.es (S. Vilchez).
}

together with bacteriophages and transposons, are considered as the main tools for prokaryotes to evolve (Norman et al., 2009) as these elements carry a pool of genes available for different bacterial species.

The occurrence of CCC DNA or plasmids in Bacillus pumilus species is not very high. Some reports revealed that only $15 \%$ of the studied strains showed some kind of CCC DNA (Lovett and Bramucci, 1975b), and others showed that no plasmids were identified at all (Yoshimura et al., 1983). Most plasmids found in B. pumilus strains (Table 1) are cryptic and do not determine for any antibiotic marker. There are only a few plasmids that have been extensively studied, but interestingly their presence in the B. pumilus strains has been associated with very surprising phenotypes. 




Many bacterial virulence factors active against insects are coded by plasmids. This is the case for the Cry toxins, proteins with insecticidal activity against a wide range of insect orders and synthesized mainly by Bacillus thuringiensis. Most of the known Cry toxins show plasmid codification, mainly in megaplamids, such as pBtoxis in B. thuringiensis var. israeliensis (Berry et al., 2002), or pIS56-285, pIS56-107 and pIS56-63 in B. thuringiensis var. thuringiensis (Murawska et al., 2013). In addition, cry genes can reside in small plasmids as well, such as pBMBt1 from $B$. thuringiensis subsp. darmstadiensis (6700 pb) (Loeza-Lara et al., 2005) or pBMB0228 from B. thuringiensis strain YBT-1518 (17,706 pb) (Guo et al., 2008).

In the case of the facultative entomopathogenic bacteria Serratia enthomophila, responsible for amber disease of the New Zealand grass grub Costelytra zealandica, the genes responsible for its virulence, sepA, sepB and sepC (Hurst et al., 2000) are also located in the large plasmid pADAP (Glare et al., 1993).

Lysinibacillus sphaericus, another entomopathogenic species has been successfully used in biological control programs to reduce populations of mosquito larvae transmitting-diseases such as malaria, filariasis, and arboviral diseases. This bacterium harbors the plasmids (pBsph) that contain the virulence factors, BinA and BinB (apart from the duplicate copy on the chromosome) mainly responsible for the death of the larvae (Hu et al., 2008).

A preliminary molecular analysis of the recently described B. pumilus 15.1 strain (Molina et al., 2010), an entomopathogenic strain active against Ceratitis capitata, the Mediterranean fruit fly (Medfly), showed the presence of at least two extrachromosomal elements when total DNA is extracted from the strain (Molina, 2010). B. pumilus is not a classic entomopathogen, therefore we hypothesized that the strain 15.1 may have acquired the capability of being toxic to $C$. capitata larvae due to the uptake of extrachromosomal material from another entomopathogenic strain.

The fact that there are not many B. pumilus strains bearing extrachromosomal DNA and that very few are well characterized prompted us to extensively characterize of one of the plasmids found in B. pumilus 15.1. Our aim was to reveal if it contains potential genes responsible for its virulence against the Medfly.

Here we report the isolation, cloning, sequencing, comparative analysis and characterization of the small plasmids found in the B. pumilus 15.1 strain.

\section{Materials and methods}

\subsection{Bacterial strains and growth conditions}

The bacterial strains used in this study were B. pumilus 15.1, B. pumilus M1 (Uad et al., 2007), and Escherichia coli XL1-Blue bearing pUC19 plasmid and E. coli DH5 $\alpha$. All the bacterial strains were grown in Luria-Bertani (LB) medium (Scharlau S.L.). B. pumilus 15.1 and $\mathrm{M} 1$ were grown at $30^{\circ} \mathrm{C}$ in a rotary shaker at $240 \mathrm{rpm}$, whilst E. coli XL-1 Blue and DH5 $\alpha$ strains were grown at $37^{\circ} \mathrm{C}$ and $240 \mathrm{rpm}$. E. coli XL-1 Blue bearing pUC19 required $100 \mu \mathrm{g} / \mathrm{ml}$ of ampicillin when cultured.

\subsection{DNA manipulation and analysis.}

Total DNA from B. pumilus strains was obtained from a mid$\log$ culture following the protocol described by Reyes-Ramirez 
and Ibarra (2008). Plasmids pBp15.1S and pUC19 were extracted from B. pumilus 15.1 and E. coli XL-1 Blue, respectively, using QIAprep ${ }^{\circledR}$ Spin Miniprep Kit (Qiagen) according to the manufacturer's instructions with some modifications. When plasmid was obtained from $B$. pumilus 15.1, cells were resuspended in TES buffer ( $30 \mathrm{mM}$ Tris base, $5 \mathrm{mM}$ EDTA, $50 \mathrm{mM}$ $\mathrm{NaCl}$; pH 8.0), supplemented with $20 \%$ sucrose, $2 \mathrm{mg} / \mathrm{ml}$ lysozyme and $1 \mu \mathrm{l} / \mathrm{ml}$ RNAse right before use instead of using P1 buffer provided by the kit. Cell suspension was incubated for 30 min at $37{ }^{\circ} \mathrm{C}$ in order to allow an extensive cell wall digestion before adding P2 buffer (provided by the kit). Total DNA and plasmid concentration was determined spectrophotometrically using a NanoDrop® Spectrophotometer ND-1000.

One microgram of pBp15.1S was individually digested with SmaI, HindIII, XbaI, EcoRI, BamHI, BglII and Sall enzymes from New England Biolabs according to the manufacturer's instructions. DNA samples were analyzed on $0.8 \%(w / v)$ agarose gels made in TBE buffer (for total DNA extractions) or TAE buffer (for DNA digestions), electrophoresed and visualized on a UVP BioDoc-It ${ }^{\mathrm{TM}}$ Imaging System.

\subsection{DNA cloning and sequencing}

HindIII or EcoRI-digested pBp15.1S DNA was ligated to HindIII or EcoRI-digested pUC19 after enzyme inactivation using T4 DNA Ligase (Invitrogen) according to the manufacturer's instructions. Chemically competent E. coli $\mathrm{DH} 5 \alpha$ cells were transformed with ligation reactions by heat shock and white colonies were screened by the Toothpick Plasmid Assay (Sambrook et al., 1989) in a 1\% agarose gel (in TAE buffer) to identify bacterial colonies containing plasmids larger than pUC19. Selected clones were kept for subsequent plasmid extraction and digestion with HindIII or EcoRI to verify the size of the inserted fragment. Both strands of each selected plasmid were sequenced using forward and reverse M13 universal primers (M13F: 5'TGTAAAACGACGGCCAGT3' and M13R: 5'CAGGAAACAGCTATGACC3') in a four capillary automatic sequencer (Applied Biosystems/Hitachi, model 3130). When forward and reverse sequences did not overlap, primerwalking technique was carried out. DNA sequences were assembled using the Lasergene software package from DNASTAR, Inc. and complete sequence of the pBp15.1S plasmid was determined.

\subsection{Bioinformatic analyses}

The pBp15.1S DNA sequence was analyzed with different bioinformatic tools. Open reading frames (ORFs) were deduced and annotated by using NCBI Glimmer v3.02 (Delcher et al., 1999; Salzberg et al., 1998), GeneMark.hmm PROKARYOTIC v2.8 (Besemer et al., 2001) and ORF finder at NCBI (Wheeler et al., 2003). The ORF sequences predicted by these tools were BLASTed using the blastn and blastp algorithms with default parameters against the GenBank database (Date: 10/07/2015). In order to obtain information about their functionality, the ORF sequences were used as queries against the protein family databases STRING v9.1 (Franceschini et al., 2013) and CATH v4.0 (Sillitoe et al., 2013), the protein domain databases ScanProsite (de Castro et al., 2006), Pfam v27.0 (Finn et al., 2014), InterPro (Hunter et al., 2012; Jones et al., 2014) and CDD (Marchler-Bauer et al., 2013). They were also analyzed with
Blast2GO (Conesa and Gotz, 2008; Conesa et al., 2005; Gotz et al., 2011, 2008) in order to obtain possible functional or location information. The results were later manually inspected to annotate and predict the biological function of these ORFs. The selected ORFs were also analyzed for signal peptide sequences with SignalP v4.0 (Petersen et al., 2011). Furhermore, the plasmid was screened for the presence of direct and inverted repeat sequences using GeneQuest from DNASTAR ${ }^{\circledR}$ Lasergene v11. The remaining non-annotated plasmid sequences were compared against the Rfam database v11.0 (Burge et al., 2013) to determine the presence of noncoding RNAs and ribo-switches. The presence of non-coding RNAs and the secondary structure of the plasmid was also checked for Rho-independent terminators with TransTermHP v2.08 (Kingsford et al., 2007). SnapGene ${ }^{\circledR}$ Viewer 2.4.3 software was used for drawing purposes. The sequence alignments created in the annotation process were made with MegAlign of DNASTAR® and Clustal W v2.0 programs (Larkin et al., 2007).

\subsection{Plasmid copy number determination}

Plasmid copy number was determined by quantitative real time PCR as previously described (Lee et al., 2006; Skulj et al., 2008; Zhong et al., 2011). Based on the genome sequence of $B$. pumilus SAFR-032, obtained from the public database of the NCBI (GenBank: CP000813.1), the smc gene was selected for being a single copy on the chromosome (Bartosik and JaguraBurdzy, 2005; Hirano, 1998) and chosen as a reference in the q-PCR. Primers sequences used are shown in Table 2. Primer design was performed using Primer3web version 4.0.0 following BIO-RAD's instructions for the SsoFast ${ }^{\mathrm{TM}}$ EvaGreen ${ }^{\circledR}$ Supermixes.

Chromosomal and plasmid amplicons were individually prepared by PCR using 300 ng of total bacterial DNA, $10 \mu \mathrm{l}$ of 10X PCR buffer, $8 \mu \mathrm{l}$ of $\mathrm{MgCl}_{2}$ ( $\left.25 \mathrm{mM}\right), 2 \mu$ of deoxynucleoside triphosphates (dNTPs) (10 mM each), $3.3 \mu \mathrm{l}$ of F_primer and R_primer ( $10 \mu \mathrm{M}$ each), $0.5 \mu \mathrm{l}$ of Taq polymerase ( $5 \mathrm{U} / \mu \mathrm{l})$, and enough MiliQ water so that the final volume of the mixture was $100 \mu \mathrm{l}$. PCR mixtures were denatured at $95{ }^{\circ} \mathrm{C}$ for $5 \mathrm{~min}$, followed by 30 cycles at $95{ }^{\circ} \mathrm{C}$ for $30 \mathrm{~s}, 55^{\circ} \mathrm{C}$ for $30 \mathrm{~s}$, and $72{ }^{\circ} \mathrm{C}$ for $30 \mathrm{~s}$ and then a final extension at $72{ }^{\circ} \mathrm{C}$ for $5 \mathrm{~min}$. Amplification was checked by electrophoresis on a $0.8 \%(w / v)$ agarose gel in TAE buffer. PCR products were cleaned using a QIAquick ${ }^{\circledR}$ PCR Purification kit (Qiagen) and concentration was determined spectrophotometrically. These PCR products were used to construct the standard curves by making five serial dilutions of both plasmid and genomic amplicons. For determining the plasmid copy number, 50 ng of total DNA of B. pumilus 15.1 from different extractions were placed as unknown samples in the reaction. All reactions were carried out in triplicate. Real-Time q-PCR reactions were performed in $10 \mu$ mixture containing $1 \mathrm{X}$ SsoFast ${ }^{\mathrm{TM}}$ EvaGreen ${ }^{\circledR}$ Supermix (Bio-Rad), 300 nM of each primer, and DNA template. RealTime q-PCR was performed in a Bio-Rad CFX96 ${ }^{\mathrm{TM}}$ Real-Time System with the following cycling conditions: $98{ }^{\circ} \mathrm{C}$ for $2 \mathrm{~min}$, followed by 39 cycles at $98{ }^{\circ} \mathrm{C}$ for $5 \mathrm{~s}$ and $55{ }^{\circ} \mathrm{C}$ for $10 \mathrm{~s}$. SYBR Green fluorescent emission was measured at the end of the elongation step. Subsequently, a melting curve program was applied with a continuous fluorescent measurement starting at $65{ }^{\circ} \mathrm{C}$ and ending at $95{ }^{\circ} \mathrm{C}$ (ramping rate of $0.5{ }^{\circ} \mathrm{C} / \mathrm{s}$ ). Cycle threshold $(\mathrm{Ct})$ and concentration (Co) were determined automatically and the standard curve was plotted using Bio- 
Table 2

Primers used for plasmid copy number (PCN) determination in real-time q-PCR assays.

\begin{tabular}{llc}
\hline Primer name & Sequence 5'-3' & Product size (bp) \\
\hline smc_F & GCTGAAAATCTCGCTTGCCA & 177 \\
smc_R & TCTTCCAGTTGTTCGGCTCC & Chromosome \\
orf7_F & GCCGGTCAGAAATTCATAGCTG & Chromosome \\
orf7_R & TAGCAACCACTCGAGTTCCAC & pBp15.1S \\
\hline
\end{tabular}

Rad CFX Manager 3.0 software. The plasmid and genomic quantity was obtained interpolating data of unknown DNA samples into the standard curves. Plasmid copy number was calculated using the equation described by Lee et al., 2006.

\subsection{Detection of ssDNA by $P C R$}

To detect ssDNA, we followed the method described by ((Booth et al., 2001) with slight modifications. Twenty nanograms of pBp15.1 was used as a template in an extension reaction from primer ssDNA2 ( $5^{\prime}$ TTTTATGGTATCTATCAT TGTATCCACCGCC $3^{\prime}$ ), designed based on the plasmid sequence (underlined). The same amount of pBp15.1 DNA was treated with S1 nuclease (Thermo Fisher Scientific) following the manufacturer's instructions. To create a ssDNA control, $20 \mathrm{ng}$ of pBp15.1 DNA was boiled at $95{ }^{\circ} \mathrm{C}$ for $5 \mathrm{~min}$ and cooled rapidly on ice. These three samples were added to $20 \mu$ of an extension mix containing dNTPs ( $250 \mu \mathrm{M})$, primer ssDNA2 (330 nM), PCR buffer (1X), $\mathrm{MgCl}_{2}(2 \mathrm{mM})$, and Taq Polymerase from EMBL $(0.5 \mathrm{U} / \mathrm{Ml})$ and incubated at $40{ }^{\circ} \mathrm{C}$ for $5 \mathrm{~min}$, and then up to $72{ }^{\circ} \mathrm{C}$ with a temperature ramp of $0.1{ }^{\circ} \mathrm{C} / \mathrm{s}$ in a Bio-Rad CFX96 ${ }^{\mathrm{TM}}$ thermocycler. Two microlitres of the extension reaction was mixed with $18 \mu$ of a PCR master mix containing dNTPs $(250 \mu \mathrm{M})$, primer ssDNA1 (330 nM) (5' TTTTATGGTATCTAT 3'), primer orf7_F (330 nM) (Table 2), PCR buffer (1X), $\mathrm{MgCl}_{2}$ (2 $\mathrm{mM})$, and Taq Polymerase from EMBL (0.5 U/ $\mu \mathrm{l})$. PCR was performed using a denaturing cycle at $95{ }^{\circ} \mathrm{C}$ for $5 \mathrm{~min}$, 30 cycles of amplification $\left(95^{\circ} \mathrm{C}\right.$ for $30 \mathrm{~s}, 40{ }^{\circ} \mathrm{C}$ for $30 \mathrm{~s}, 72{ }^{\circ} \mathrm{C}$ for $1 \mathrm{~min}$ ) and a final cycle for extension at $72{ }^{\circ} \mathrm{C}$ for $5 \mathrm{~min}$. Subsequently, $5 \mu \mathrm{l}$ of each sample was analyzed on a $0.8 \%$ agarose gel in TAE $1 \mathrm{X}$ containing SYBR Safe.

\subsection{Nucleotide sequence accession number}

The sequence of $\mathrm{pBp} 15.1 \mathrm{~S}$ from $B$. pumilus 15.1 determined in this study was deposited at the GenBank database under the accession No. KM348008.

\section{Results and discussion}

\subsection{Plasmid detection, pBp15.1S sub-cloning and sequencing}

When a total DNA extraction from B. pumilus 15.1 was analyzed by agarose electrophoresis, at least two extrachromosomal
A

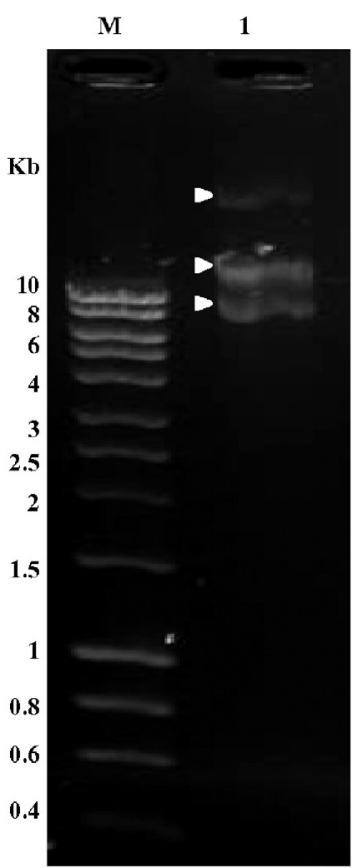

B


C
3

M

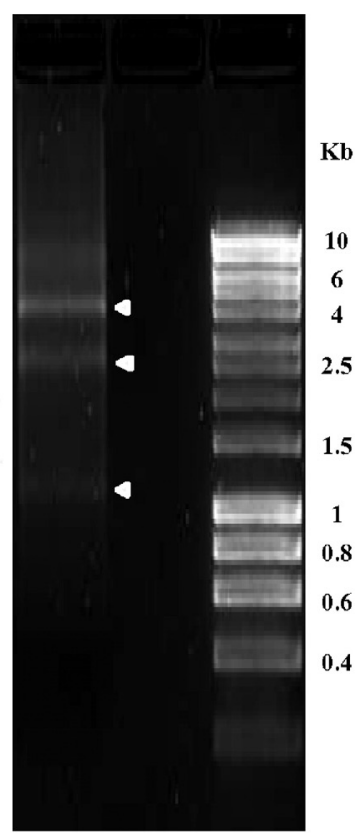

Fig. 1. DNA electrophoresis in $0.8 \%$ agarose. (A) Total DNA extraction from B. pumilus 15.1 (lane 1) and B. pumilus M1 (lane 2); $\mathrm{M}_{\mathrm{A}}$ shows a molecular weight marker (250 bp-12 kb fromStratagene). HindIII (B) and EcoRI (C) digestion of the pBp15.1S plasmid. $\mathrm{M}_{\mathrm{B}}$ shows a molecular weight marker (HyperLadder I from Bioline) in kb. Reverse image black to white is shown in order to increase visibility of the DNA. 
DNA elements were detected (Fig. 1A lane 1), one with an apparent size of approximately $7 \mathrm{~kb}$ and other with an apparent size larger than the band corresponding to the bacterial chromosome. The B. pumilus M1 strain was used as a control to identify the chromosomal DNA size (Fig. 1A, lane 2 ). We concluded that the strain B. pumilus 15.1 contained at least one plasmid (named pBp15.1S) and one megaplasmid (named pBp15.1B) in its cytoplasm. Here, we focus on the characterization of the $\mathrm{pBp} 15.1 \mathrm{~S}$ plasmid.

When pBp15.1S was extracted and separated from the megaplasmid pBp15.1B (by using a plasmid extraction kit with molecular weight cut-off) and digested with seven restriction enzymes (SmaI, HindIII, XbaI, EcoRI, BamHI, BglII and SalI) (data not shown) only HindIII and EcoRI rendered fragments smaller than $7 \mathrm{~kb}$. HindIII digestion rendered two fragments of approximately 2.5 and $1.5 \mathrm{~kb}$, respectively (Fig. 1B) whilst EcoRI digestion rendered three fragments of $4,2.5$ and $1.1 \mathrm{~kb}$ respectively (Fig. 1C). Given that the size of the plasmid was around $7 \mathrm{~kb}$, we hypothesized that there exist either a large number of small HindIII fragments or that there were two DNA fragments (possibly the 2.5 fragment) showing a similar size that was not resolved in a $0.8 \%$ agarose gel.

EcoRI and HindIII fragments were cloned into pUC19 plasmid and positive transformants were screened, isolated and sequenced. Table 3 shows the name of the plasmids obtained, the exact size of the fragments inserted, and the position of the restriction sites in the complete sequence of the pBp15.1S plasmid.

\section{Sequence assembling and comparative analysis of the pBp15.1S plasmid}

The sequence of each clone was assembled with the help of Lasergene software from DNASTAR and ClustalW algorithm and the obtained complete sequence of pBp15.1S was submitted to the GenBank. Sequence analysis showed that the plasmid pBp15.1S is a circular molecule with $7785 \mathrm{bp}$ in length and with a $\mathrm{G}+\mathrm{C}$ content of $35.7 \%$. A restriction enzyme analysis using SeqBuilder of DNASTAR showed that Xbal and Bgll enzymes have a unique cleavage site on pBp15.1S, 3 EcoRI sites, 6 HindIII sites and no specific cleavage sites for Smal, BamHI, and SalI (Fig. 2), confirming our previous experimental results on DNA digestion.

\subsection{ORF analysis}

Analysis using several algorithms and approaches showed that pBp15.1S plasmid had 30 potential ORFs, but only 11

Table 3

Recombinant plasmids obtained from pBp15.1S EcoRI and HindIII digestion, insert size and position of restriction sites at the complete sequence.

\begin{tabular}{llll}
\hline Digestion & $\begin{array}{l}\text { Recombinant } \\
\text { plasmid names }\end{array}$ & $\begin{array}{l}\text { Insert size } \\
(\mathrm{bp})\end{array}$ & $\begin{array}{l}\text { Position at the } \\
\text { complete sequence }\end{array}$ \\
\hline \multirow{2}{*}{ EcoRI } & pDG_7 & 4084 & $6165-2463$ \\
& pDG_4 & 2588 & $2464-5051$ \\
& pDG_3 & 1113 & $5052-6164$ \\
HindIII & pDG_5 & 2615 & $7058-1887$ \\
& pDG_2 & 2564 & $4494-7057$ \\
& pDG_6 & 1583 & $1888-3470$ \\
& pDG_1 & 379 & $4115-4493$ \\
\hline
\end{tabular}

showed similarities to known proteins from the NCBI nonredundant microbial protein database (Table 4, Fig. 2).

ORF1 showed 94\% identity with the Rep protein from Marinomonas sp. D104, involved in the initiation of replication. The search against Pfam revealed a strong match between ORF1 and the Rep_1 family (PF01446) and annotation predicted with Blast2GO for this ORF was DNA replication as a biological process, DNA binding as a molecular function and as a cellular component extrachromosomal circular DNA. The putative protein encoded by ORF1 showed the three conserved motifs characteristic of RCR (rolling circle replication) Rep proteins described by Ilyina and Koonin (1992) and one motif described by Yang and McFadden (1993). Upstream of the rep gene, a non-coding region (spanning from 298 to $354 \mathrm{bp}$ ) known as double strand origin (dso) or plus-origin was identified. This region was similar to the approximately $58 \mathrm{bp}$ dso region of the Bacillus subtilis plasmid pC194 described by Gros et al. (1987) and similar to the dso region from other B. subtilis (and related species) plasmids with small rolling circle replication mechanisms (Guglielmetti et al., 2007). In this region, the conserved nick-site sequence 5'TCTTG*ATAC3' was identified between position 308 and 316 . The nick-site $\left(^{*}\right)$ was 160 bp upstream of the start codon of the Rep protein. The dso region and the rep gene observed are predicted to constitute the replication module of the $\mathrm{pBp} 15.1 \mathrm{~S}$ plasmid.

ORF2 showed identity with a hypothetical protein with an unknown function that is highly conserved in plasmids from B. subtilis and B. pumilus strains. Using the SignalP algorithm, we showed that ORF2 contained a predicted signal peptide at the $\mathrm{N}$ terminal end and a cleavage site between position 34 and 35.

ORF3, ORF4, ORF5 and ORF6 showed similarity with different hypothetical proteins from the Bacillus genus. The SignalP analysis showed that only ORF4 had a predicted signal peptide and a cleavage site between the amino acids 26 and 27.

ORF7, ORF8 and ORF9 showed a high identity with the hypothetical proteins ZZ1 (96\%), ZZ2 (91\%) and ZZ4 (84\%) from the plasmid pPZZ84 of B. pumilus ZZ84 strain. Apart from the identity, ORF7, ORF8 and ORF9 showed the same gene microsynteny and orientation as ZZ1, ZZ2, and ZZ4. ORF7 contained a predicted signal peptide and a cleavage site between the position 30 and 31 of the hypothetical protein. ORF8 showed two relevant protein domains, the MerR_1 domain (position 9-76 aa) and the DUF3967 domain (position 135-169 aa). MerR_1 or MerR-type HTH family (PF13411) is a transcriptional regulator with helix-turn-helix DNA binding regions at the $\mathrm{N}$-terminal end. Most MerR-type transcriptional regulators respond to environmental stimuli, such as heavy metals, oxidative stress or antibiotics (Brown et al., 2003). DUF3967 (PF13152) is a protein family of unknown function frequently found in the Firmicutes phylum.

Even the inter-genetic regions between ORF7, ORF8 and ORF9 were similar to those present in plasmid pPZZ84. The gene cluster in pPZZ84 comprises of four ORFs (ZZ1-ZZ4) whilst in plasmid pBp15.1S comprises of only three (ORF7ORF9). A detailed analysis and comparison of the sequences of both plasmids showed that ZZ3 ORF was almost completely deleted from the cluster present in plasmid pBp15.1S (and hence, not detected as a putative ORF).

The last two ORFs found in the plasmid, ORF10 and ORF11, showed an overlapping distribution i.e. the putative $\mathrm{N}$-terminal 

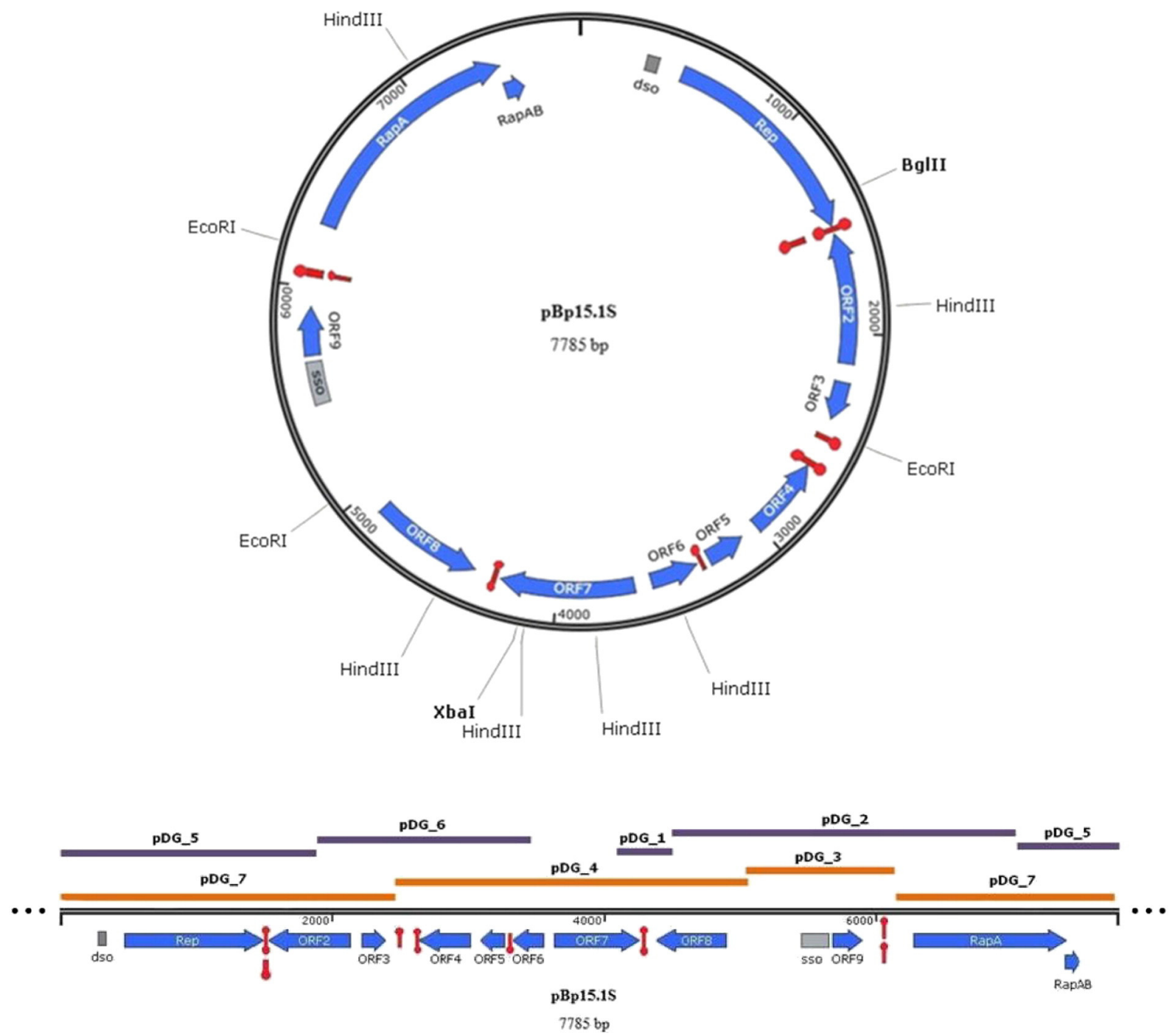

Fig. 2. Circular map of pBp15.1S from B. pumilus strain 15.1. The positions of the eleven ORFs are shown as arrows including Rep, RapA and RapAB ORFs. The positions of the putative $d s o$ and sso regions are indicated by boxes and ITs are indicated by red hairpins. Inserts present in pDGi plasmids are detailed as well in a linear map. (For interpretation of the references to color in this figure legend, the reader is referred to the web version of this article.)

end of the ORF11 begins at the last codons of ORF10. An analysis of ORF10 and ORF11 predicted the presence of a signal peptide and a cleavage site between position 23 and 24 in ORF11. ORF10 and ORF11 showed high identity with RapA and RapAB proteins from the B. subtilis pPOD2000 plasmid (100\% identity) and B. pumilus pPL7065 plasmid (98\% identity). Although the RapAB is not annotated as such in plasmid pPL7065, it contains a region 97\% identical to RapAB from pPOD2000.

A Pfam analysis of ORF10 showed significant alignments at positions 178-247 and 256-280 with TPR_12 (PF13424) and TPR 1 (PF00515) family. The TPR family is characterized by the presence of tetratricopeptide repeats, a 34 aa structural motif present in proteins from diverse organisms and in a variety of subcellular locations. Proteins with this motif are involved in cell cycle control, transcriptional control, mitochondrial and peroxisomal protein transport, neurogenesis and protein folding (D'Andrea and Regan, 2003; Lamb et al., 1995). The gene ontology analysis assigned a hydrolase activity to ORF10 as its molecular function.

RapA belongs to the family of Rap proteins, response regulator aspartyl-phosphate phosphatases that are able to directly (Core and Perego, 2003; Ogura et al., 2003) or indirectly (Jiang et al., 2000; Perego et al., 1994) inhibit the transcriptional factors involved in important cellular process such as sporulation, bacterial competence, or the production of enzymes or antibiotics. For example, RapA phosphatase prevents sporulation in B. subtilis by dephosphorylation of the SpoOF-P factor, and Rap I controls the excision of integrative and conjugative elements (ICEs) from the chromosome (Auchtung et al., 2005). The phosphatase activity of RapA is regulated by a small protein, PhrA, encoded by a downstream overlapping ORF (Perego and Hoch, 1996). This overlap is frequently seen among the Rap proteins. More specifically, PhrA is synthetized as a 44 aa precursor that is processed by a series of proteolytic events resulting in the active pentapeptide 
Table 4

Comparative analysis of ORFs found in plasmid pBp15.1S from B. pumilus 15.1 .

\begin{tabular}{|c|c|c|c|c|c|c|c|c|c|}
\hline Orf name & Strand & Size (bp) & (Start-stop) & Size (aa) & Best BLAST match [Comments] & Accession No. & Identity $^{\mathrm{a}}(\%)$ & No. positive/No. examined ${ }^{\mathrm{b}}(\%)$ & E-value $^{c}$ \\
\hline \multirow[t]{3}{*}{ ORF1 } & \multirow[t]{3}{*}{+} & \multirow[t]{3}{*}{1023} & \multirow[t]{3}{*}{ 473-1495 } & \multirow[t]{3}{*}{340} & $\begin{array}{l}\text { Rep protein, Marinomonas sp. D104 [pfam01446; } \\
\text { gene = "rep40"/note = "involved in initiation of replication"] }\end{array}$ & ETI59042.1 & $320 / 340(94 \%)$ & $334 / 340(98 \%)$ & 0 \\
\hline & & & & & Rep protein, Bacillus subtilis IAM1232 plasmid pTA1040 & AAC44406.1 & $317 / 338(94 \%)$ & $328 / 338(97 \%)$ & 0 \\
\hline & & & & & Rep, Bacillus pumilus SH1451 plasmid pSH1452 & AAB71488.1 & $311 / 341(91 \%)$ & $329 / 341(96 \%)$ & 0 \\
\hline \multirow[t]{2}{*}{ ORF2 } & \multirow[t]{2}{*}{-} & \multirow[t]{2}{*}{606} & \multirow[t]{2}{*}{$1533-2138$} & \multirow[t]{2}{*}{201} & Product unknown, Bacillus pumilus & \multirow[t]{2}{*}{ AAB91479.1 } & \multirow[t]{2}{*}{$185 / 201(92 \%)$} & \multirow[t]{2}{*}{$189 / 201(94 \%)$} & \multirow[t]{2}{*}{$8 \mathrm{E}-122$} \\
\hline & & & & & ATCC 12140 plasmid pPL10 [name: Orf5, putative exported protein] & & & & \\
\hline \multirow[t]{2}{*}{ ORF3 } & \multirow[t]{2}{*}{+} & \multirow[t]{2}{*}{180} & \multirow{2}{*}{$2226-2405$} & \multirow[t]{2}{*}{59} & Hypothetical protein, Bacillus sp. SB47. & WP_026579015 & $52 / 59(88 \%)$ & $55 / 59(93 \%)$ & $2 \mathrm{E}-26$ \\
\hline & & & & & Hypothetical protein, Bacillus sonorensis. & WP_029419235 & $33 / 59(56 \%)$ & $44 / 59(74 \%)$ & $1 \mathrm{E}-14$ \\
\hline \multirow[t]{2}{*}{ ORF4 } & \multirow[t]{2}{*}{-} & \multirow[t]{2}{*}{372} & \multirow[t]{2}{*}{ 2644-3015 } & \multirow[t]{2}{*}{123} & Hypothetical protein IAU_04559, Bacillus cereus IS075 & EJP86132.1 & $36 / 93(39 \%)$ & $50 / 93(54 \%)$ & 2E-09 \\
\hline & & & & & $\begin{array}{l}\text { Hypothetical protein Bsph_1099, } \\
\text { Lysinibacillus sphaericus C3-41. }\end{array}$ & YP_001696839 & $35 / 89(39 \%)$ & $47 / 89(52 \%)$ & $1 \mathrm{E}-08$ \\
\hline ORF5 & - & 183 & $3095-3277$ & 60 & $\begin{array}{l}\text { Hypothetical protein BAT_3812, } \\
\text { Bacillus pumilus ATCC } 7061\end{array}$ & EDW20251.1 & $20 / 28(71 \%)$ & $22 / 28(79 \%)$ & $2 \mathrm{E}-04$ \\
\hline ORF6 & - & 225 & $3338-3562$ & 74 & Hypothetical protein, Bacillus pumilus & WP_017358598.1 & $41 / 66(62 \%)$ & $54 / 66(82 \%)$ & $1 \mathrm{E}-19$ \\
\hline ORF7 & + & 624 & $3642-4265$ & 207 & Hypothetical protein, Bacillus pumilus ZZ84 plasmid pPZZ84 [note = "ZZ1"] & ACZ28698.1 & 199/207 (96\%) & $204 / 207$ (99\%) & $2 \mathrm{E}-142$ \\
\hline \multirow[t]{2}{*}{ ORF8 } & \multirow[t]{2}{*}{-} & 513 & $4388-4900$ & 170 & ZZ2, Bacillus pumilus ZZ84 plasmid pPZZ84 & ACZ28699.1 & $155 / 170(91 \%)$ & $162 / 170(95 \%)$ & $4 \mathrm{E}-106$ \\
\hline & & & & & ORF4, Bacillus subtilis plasmid pPOD2000 & AAA99154.1 & 100/104 (96\%) & $102 / 104(98 \%)$ & $2 \mathrm{E}-65$ \\
\hline ORF9 & + & 225 & $5686-5910$ & 74 & $\begin{array}{l}\text { ZZ4, Bacillus pumilus ZZ84 } \\
\text { plasmid pPZZ84 }\end{array}$ & ACZ28701.1 & $62 / 74(84 \%)$ & $63 / 74(85 \%)$ & $1 \mathrm{E}-28$ \\
\hline ORF10 & + & 1119 & $6291-7409$ & 372 & RapA, Bacillus subtilis, plasmid pPOD2000 & AAA99153.1 & $372 / 372(100 \%)$ & $372 / 372(100 \%)$ & 0 \\
\hline & & & & & $\begin{array}{l}\text { RapA, Bacillus pumilus, ATCC } 7065 \\
\text { plasmid pPL7065 [response regulator aspartate phosphatase] }\end{array}$ & AA072995.1 & $364 / 372(98 \%)$ & $368 / 372(99 \%)$ & 0 \\
\hline ORF11 & + & 117 & 7399-7515 & 38 & RapAB, Bacillus subtilis, plasmid pPOD2000 & AAA99152.1 & $38 / 38(100 \%)$ & $38 / 38(100 \%)$ & $7,00 \mathrm{E}-17$ \\
\hline
\end{tabular}

${ }^{a}$ Identity is the degree of correspondence between two sequences. Number of amino acid identities/Number of amino acids compared.

b Positive scores indicate substitutions that occur frequently/Number of amino acids examined.

${ }^{c}$ E-value represents the number of different alignments with scores equivalent to or better than score, that are expected to occur in a database search by chance. 


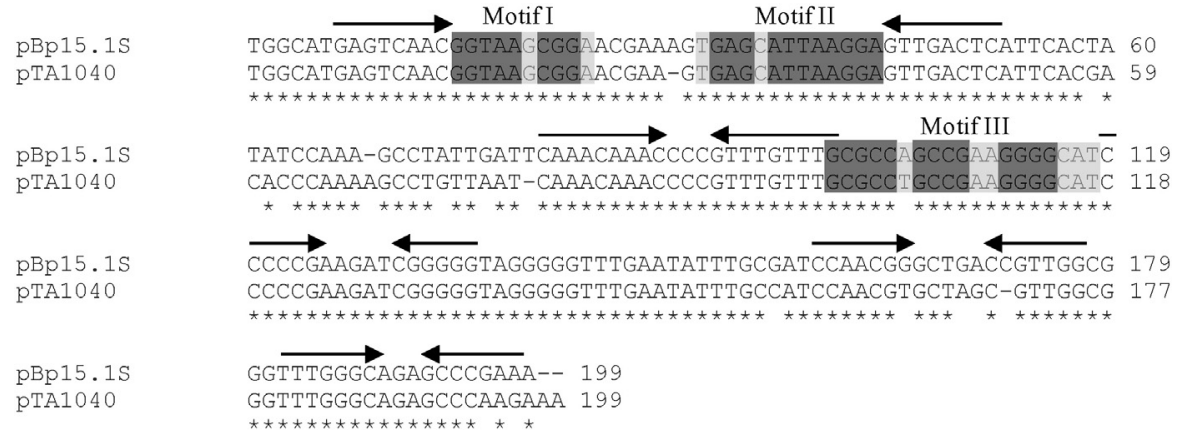

Fig. 3. Clustal alignment of the 5459-5657 region of pBp15.1S and the annotated sso region of the $B$. subtilis pTA1040 plasmid. The figure shows the inverted repeats detected in pBp15.1S sequence as arrows. Conserved motifs in SsoT are shaded, and ssoT2 subclass is light shaded.

ARNQT (Perego, 1997). This pentapeptide specifically inhibits the phosphatase activity of RapA.

RapA proteins have been previously described to be present in B. pumilus SAFR-032 genome (No. access CP000813.1). This strain contains four RapA proteins, and RapH, RapD1, RapD2, RapE and RapK belonging to the same family. Out of these 9 proteins, only RapA1, RapA2 and RapH showed the two-protein system Rap-Phr. These three chromosomal Rap-Phr members showed some identity with the plasmidic ORF10 [40\% with RapA1 (ABV61825.1), 40\% with RapA2 (ABV61893.1), and 37.9\% with RapH (ABV61816.1)] but very low identity with ORF11 [23.68\% with PhrA1 (ABV61826.1), 10.53\% with PhrA2 (ABV61894.1) and 10.53\% PhrH (ABV61817.1)].

Taking into account all of the above-mentioned facts, we postulate that ORF10 and ORF11 from pBp15.1S may represent a sensing and regulatory system specific for the plasmid, different from those chromosomally encoded.

\subsection{Transcription terminator, secondary structure and non-coding RNA analysis}

TransTermHP v2.08 was used for predicting intrinsic terminators (ITs) in pBp15.1S sequence. Eleven putative ITs with high confidence value (80-100) were found in five out of the eleven ORFs predicted in the plasmid (Fig. 2). All, except the one between ORF5 and ORF6, were predicted to be at the 3' end of a putative ORF. This terminator was located $28 \mathrm{nt}$ upstream of the ORF5 start codon, probably in the promoter region.

An analysis of the pBp15.1S sequence with DNASTAR software searching for direct and inverted repeats was also performed (data not shown). A region rich in inverted repeats was localized between position 5459 and 5657, showing five inverted repeats that may generate stem-loop structures. This region was almost identical (93\% identity) to the annotated sso region (single strand origin) of the B. subtilis plasmid pTA1040

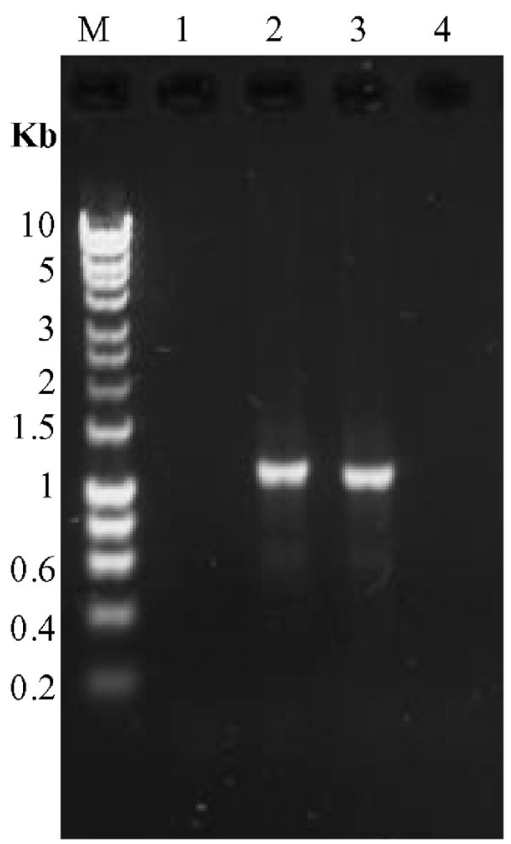

Fig. 4. PCR products obtained with primers orf7 and ssDNA1 using molecules created by primer extensions from ssDNA2 as templates. Lane 1 contained no template (PCR negative control). In lane 2 template was obtained by extension from a boiled and cooled on ice pBp15.1S preparation (positive control). In lane 3 template was obtained by extension from a pBp15.1S preparation and in lane 4 from a S1 treated pBp15.1S preparation. M shows Molecular weight marker in kb (HyperLadder I from Bioline). 
(ID No. U32378.1). Conserved motifs typical of ssoT type were identified (Fig. 3) (Seery and Devine, 1993), so it is highly probable that this region may represent the sso region, where the host polymerases start the conversion of the ssDNA into dsDNA (synthesis of the lagging strand). Accordingly to their sequence, sso regions can be classified into groups and plasmids pPL7065, pPOD2000, pPL10, pTA1040, and pSH1452 belong to the ssoT2 subgroup (Guglielmetti et al., 2007). Given its high identity, pBp15.1S could also be classified as a member of this subgroup.

The sequence of $\mathrm{pBp} 15.1 \mathrm{~S}$ was analyzed using Rfam for relevant non-coding RNAs. The in silico analysis showed a region of the plasmid (between 5464 and 5520 positions) with a high score (E-value 1.9e-10) for the Bacillus-plasmid RNA family (RF01691). pBp15.1S has this RNA-motif within the predicted sso region, as well as other $B$. pumilus plasmids such as pPL10, pPZZ84, pL7065, pSH1452 and pMMH1 and other plasmids from Bacillus cereus, B. thuringiensis or B. subtilis. Although the function of the RNA Bacillus-plasmid motif is unknown, its secondary structure suggests a cis-antisense RNA that might regulate plasmid copy number (Weinberg et al., 2010) or a RNA that acts as a primer to promote the lagging strand replication of the plasmid (Guglielmetti et al., 2007).

\section{Determination of the copy number of pBp15.1S}

A quantitative real time PCR method was used to determine the copy number of plasmid $\mathrm{pBp} 15.1 \mathrm{~S}$ present in B. pumilus 15.1 cells in exponential growth phase (Lee et al., 2006). For quantification purposes, the chromosomal smc gene was used as a reference of a single copy gene and a region of $199 \mathrm{bp}$ was used for plasmid detection. Five-fold serial dilutions of PCRamplified DNA (0.05-0.000005 ng/ $\mathrm{ll}$ ) were used to construct linear standard curves $\left(r^{2}>0.99\right)$. Based on the data obtained, the copy number of $\mathrm{pBp} 15.1 \mathrm{~S}$ was calculated to be approximately $33 \pm 2$ copies per chromosome.

\section{Detection of ssDNA in pBp15.1 S}

Data derived from the in silico analysis of the pBp15.1S sequence showed a predicted $d s$ region and a rep gene, essential elements for the replication of plasmids with a Rolling Circle Replication mechanism. The presence of ssDNA intermediates would demonstrate that $\mathrm{pBp} 15.1 \mathrm{~S}$ follows the RCR mechanisms. To show this, an extension from primer ssDNA2, followed by a PCR with orf7 and ssDNA1 primers was performed using a preparation of untreated and S1 treated pBp15.1S as templates. As a positive control, a boiled and cooled on ice preparation of pBp15.1S was used in parallel. The results show (Fig. 4) that ssDNA was present in the pBp15.1S preparation (lane 3) while it was not detected when pBp15.1S was treated with S1 enzyme (lane 4), suggesting that the replication mechanism for pBp15.1S follows the RCR mechanism.

\section{Conclusions}

The plasmid pBp15.1S from B. pumilus 15.1 is a $7785 \mathrm{bp}$ circular, covalently closed molecule, with approximately 33 copies per chromosome. It codes for 11 relevant ORFs, with only 3 of them being similar to known proteins. ORF1 was homologous to the Rep protein, described as involved in plasmid replication, and ORFs 10 and 11 were homologous to the RapA and RapAB proteins, of the Rap protein family which are involved in the regulation of many important cells processes. The remaining ORFs were highly similar to other plasmid proteins but no known function could be identified for them.

A conserved region for the initiation of replication, the double strand origin (or dso region), and for the initiation of the conversion of the ssDNA to dsDNA, the single strand region (or SSo), was identified by sequence comparison and by secondary structure analysis. In addition, the existence of ssDNA was demonstrated experimentally, suggesting that pBp15.1S plasmid has a small rolling cycle (SRC) replication mechanisms, as many other plasmids from Gram-positive bacteria (Khan, 2005).

Apart from ORF1, ORF10 and ORF11, the rest of the ORFs present in $\mathrm{pBp} 15.1 \mathrm{~S}$ have no known function. However, a group of three ORFs (ORF7-ORF9) showed similarity with plasmid pPZZ84 from the B. pumilus strain ZZ84 (Zhang et al., 2010). The fact that this gene cluster has been found in two plasmids from a very distant isolated $B$. pumilus strains may indicate that the genes from the cluster are related in their function.

The analysis of the pBp15.1S sequence did not show similarity with any known virulence factors either in bacteria or any other organisms. Hence, the presence of the plasmid in the strain $B$. pumilus 15.1 may not be linked with its toxicity against $C$. capitata, unless any of the putative ORFs with unknown functions code for a novel virulence factor. However, four out of the 11 ORFs found in pBp15.1S (ORF2, ORF4, ORF7, and ORF11) were predicted to show a signal peptide and a processing site, so they could potentially be considered secreted proteins. As many virulence factors are secreted outside the cell, we still cannot rule out the possibility that these proteins are related with toxicity. This hypothesis is currently being experimentally ratified.

\section{Acknowledgments}

We thank the SENESCYT-ECUADOR for the scholarship that supported Diana C. Garcia-Ramon and the Spanish Agency for International Co-operation (AECI) for the scholarship that supported C. Alfonso Molina. This work was partially funded by the Spanish Ministry of Science and Innovation through the project CGL2008-02011/BOS and by the Consejeria de Ciencia e Innovacion from Junta de Andalucía through their research Program "Proyectos de Excelencia” (grant ID: AGR-6409).

\section{References}

Auchtung, J.M., Lee, C.A., Monson, R.E., Lehman, A.P., Grossman, A.D., 2005. Regulation of a Bacillus subtilis mobile genetic element by intercellular signaling and the global DNA damage response. Proc. Natl. Acad. Sci. U. S. A. 102, 12554-12559.

Bartosik, A.A., Jagura-Burdzy, G., 2005. Bacterial chromosome segregation. Acta Biochim. Pol. 52, 1-34.

Berry, C., O'Neil, S., Ben-Dov, E., Jones, A.F., Murphy, L., Quail, M.A., Holden, M.T., Harris, D., Zaritsky, A., Parkhill, J., 2002. Complete sequence and organization of pBtoxis, the toxin-coding plasmid of Bacillus thuringiensis subsp. Israelensis. Appl. Environ. Microbiol. 68, 5082-5095.

Besemer, J., Lomsadze, A., Borodovsky, M., 2001. GeneMarkS: a self-training method for prediction of gene starts in microbial genomes. Implications for finding sequence motifs in regulatory regions. Nucleic Acids Res. 29, 2607-2618.

Booth, C., Griffith, E., Brady, G., Lydall, D., 2001. Quantitative amplification of single-stranded DNA (QAOS) demonstrates that CDC13-1 mutants generate ssDNA in a telomere to centromere direction. Nucleic Acids Res. 29, 4414-4422. 
Brown, N.L., Stoyanov, J.V., Kidd, S.P., Hobman, J.L., 2003. The MerR family of transcriptional regulators. FEMS Microbiol. Rev. 27, 145-163.

Burge, S.W., Daub, J., Eberhardt, R., Tate, J., Barquist, L., Nawrocki, E.P., Eddy, S.R., Gardner, P.P., Bateman, A., 2013. Rfam 11.0: 10 years of RNA families. Nucleic Acids Res. 41, D226-D232.

Conesa, A., Gotz, S., 2008. Blast2GO: a comprehensive suite for functional analysis in plant genomics. Int. J. Plant Genom. 2008, 619832.

Conesa, A., Gotz, S., Garcia-Gomez, J.M., Terol, J., Talon, M., Robles, M., 2005. Blast2GO: a universal tool for annotation, visualization and analysis in functional genomics research. Bioinformatics 21, 3674-3676.

Core, L., Perego, M., 2003. TPR-mediated interaction of RapC with ComA inhibits response regulator-DNA binding for competence development in Bacillus subtilis. Mol. Microbiol. 49, 1509-1522.

D'Andrea, L.D., Regan, L., 2003. TPR proteins: the versatile helix. Trends Biochem. Sci. 28, 655-662.

de Castro, E., Sigrist, C.J., Gattiker, A., Bulliard, V., Langendijk-Genevaux, P.S., Gasteiger, E., Bairoch, A., Hulo, N., 2006. ScanProsite: detection of PROSITE signature matches and ProRule-associated functional and structural residues in proteins. Nucleic Acids Res. 34, W362-W365.

Delcher, A.L., Harmon, D., Kasif, S., White, O., Salzberg, S.L., 1999. Improved microbial gene identification with GLIMMER. Nucleic Acids Res. 27, 4636-4641.

Finn, R.D., Bateman, A., Clements, J., Coggill, P., Eberhardt, R.Y., Eddy, S.R., Heger, A., Hetherington, K., Holm, L., Mistry, J., et al., 2014. Pfam: the protein families database. Nucleic Acids Res. 42, D222-D230.

Franceschini, A., Szklarczyk, D., Frankild, S., Kuhn, M., Simonovic, M., Roth, A. Lin, J., Minguez, P., Bork, P., von Mering, C., et al., 2013. STRING v9.1: protein-protein interaction networks, with increased coverage and integration. Nucleic Acids Res. 41, D808-D815.

Glare, T.R., Corbett, G.E., Sadler, T.J., 1993. Association of a large plasmid with amber disease of the New Zealand grass grub, Costelytra zealandica, caused by Serratia entomophila and Serratia proteamaculans. J. Invertebr. Pathol. 62, 165-170.

Gotz, S., Garcia-Gomez, J.M., Terol, J., Williams, T.D., Nagaraj, S.H., Nueda, M.J., Robles, M., Talon, M., Dopazo, J., Conesa, A., 2008. High-throughput functional annotation and data mining with the Blast2GO suite. Nucleic Acids Res. 36, 3420-3435.

Gotz, S., Arnold, R., Sebastian-Leon, P., Martin-Rodriguez, S., Tischler, P., Jehl, M.A., Dopazo, J., Rattei, T., Conesa, A., 2011. B2G-FAR, a species-centered GO annotation repository. Bioinformatics 27, 919-924.

Gros, M.F., te Riele, H., Ehrlich, S.D., 1987. Rolling circle replication of singlestranded DNA plasmid pC194. EMBO J. 6, 3863-3869.

Guglielmetti, S., Mora, D., Parini, C., 2007. Small rolling circle plasmids in Bacillus subtilis and related species: organization, distribution, and their possible role in host physiology. Plasmid 57, 245-264.

Guo, S., Liu, M., Peng, D., Ji, S., Wang, P., Yu, Z., Sun, M., 2008. New strategy for isolating novel nematicidal crystal protein genes from Bacillus thuringiensis strain YBT-1518. Appl. Environ. Microbiol. 74, 6997-7001.

Hasnain, S., Thomas, C.M., 1996. Two related rolling circle replication plasmids from salt-tolerant bacteria. Plasmid 36, 191-199.

Hendrick, C.A., Johnson, L.K., Tomes, N.J., Smiley, B.K., Price, J.P., 1991a. Insertion of Tn916 into Bacillus pumilus plasmid pMGD302 and evidence for plasmid transfer by conjugation. Plasmid 26, 1-9.

Hendrick, C.A., Smiley, B.K., Shelley, T.H., Tomes, N.J., 1991b. Use of a plasmid DNA probe to monitor populations of Bacillus pumilus inoculant strains in hay. Appl. Environ. Microbiol. 57, 686-693.

Hirano, T., 1998. SMC protein complexes and higher-order chromosome dynamics. Curr. Opin. Cell Biol. 10, 317-322.

Hu, X., Fan, W., Han, B., Liu, H., Zheng, D., Li, Q., Dong, W., Yan, J., Gao, M., Berry, C., et al., 2008. Complete genome sequence of the mosquitocidal bacterium Bacillus sphaericus C3-41 and comparison with those of closely related Bacillus species. J. Bacteriol. 190, 2892-2902.

Hunter, S., Jones, P., Mitchell, A., Apweiler, R., Attwood, T.K., Bateman, A., Bernard, T., Binns, D., Bork, P., Burge, S., et al., 2012. InterPro in 2011: new developments in the family and domain prediction database. Nucleic Acids Res. 40, D306-D312.

Hurst, M.R., Glare, T.R., Jackson, T.A., Ronson, C.W., 2000. Plasmid-located pathogenicity determinants of Serratia entomophila, the causal agent of amber disease of grass grub, show similarity to the insecticidal toxins of Photorhabdus luminescens. J. Bacteriol. 182, 5127-5138.

Ilyina, T.V., Koonin, E.V., 1992. Conserved sequence motifs in the initiator proteins for rolling circle DNA replication encoded by diverse replicons from eubacteria, eucaryotes and archaebacteria. Nucleic Acids Res. 20 (3) 3279-3285

Jiang, M., Grau, R., Perego, M., 2000. Differential processing of propeptide inhibitors of Rap phosphatases in Bacillus subtilis. J. Bacteriol. 182, 303-310.

Jones, P., Binns, D., Chang, H.Y., Fraser, M., Li, W., McAnulla, C., McWilliam, H., Maslen, J., Mitchell, A., Nuka, G., et al., 2014. InterProScan 5: genome-scale protein function classification. Bioinformatics 30, 1236-1240.
Khan, S.A., 2005. Plasmid rolling-circle replication: highlights of two decades of research. Plasmid 53, 126-136.

Kingsford, C.L., Ayanbule, K., Salzberg, S.L., 2007. Rapid, accurate, computational discovery of Rho-independent transcription terminators illuminates their relationship to DNA uptake. Genome Biol. 8, R22.

Lamb, J.R., Tugendreich, S., Hieter, P., 1995. Tetratrico peptide repeat interactions: to TPR or not to TPR? Trends Biochem. Sci. 20, 257-259.

Larkin, M.A., Blackshields, G., Brown, N.P., Chenna, R., McGettigan, P.A., McWilliam, H., Valentin, F., Wallace, I.M., Wilm, A., Lopez, R., et al., 2007. Clustal W and clustal X version 2.0. Bioinformatics 23, 2947-2948.

Lee, C.L., Ow, D.S., Oh, S.K., 2006. Quantitative real-time polymerase chain reaction for determination of plasmid copy number in bacteria. J. Microbiol. Methods 65, 258-267.

Loeza-Lara, P.D., Benintende, G., Cozzi, J., Ochoa-Zarzosa, A., Baizabal-Aguirre, V.M., Valdez-Alarcon, J.J., Lopez-Meza, J.E., 2005. The plasmid pBMBt1 from Bacillus thuringiensis subsp. darmstadiensis (INTA Mo14-4) replicates by the rolling-circle mechanism and encodes a novel insecticidal crystal proteinlike gene. Plasmid 54, 229-240.

Lovett, P.S., 1973. Plasmid in Bacillus pumilus and the enhanced sporulation of plasmid-negative variants. J. Bacteriol. 115, 291-298.

Lovett, P.S., Bramucci, M.G., 1974. Biochemical studies of two Bacillus pumilus plasmids. J. Bacteriol. 120, 488-494.

Lovett, P.S., Bramucci, M.G., 1975a. Evidence for a nonrandom base sequence in a Bacillus pumilus plasmid: EcoR1 endonuclease digestion of pPL576. J. Bacteriol. 123, 377-379.

Lovett, P.S., Bramucci, M.G., 1975b. Plasmid deoxyribonucleic acid in Bacillus subtilis and Bacillus pumilus. J. Bacteriol. 124, 484-490.

Lovett, P.S., Burdick, B.D., 1973. Cryptic plasmid in Bacillus pumilus ATCC 7065. Biochem. Biophys. Res. Commun. 54, 365-370.

Lovett, P.S., Duvall, E.J., Keggins, K.M., 1976. Bacillus pumilus plasmid pPL10: properties and insertion into Bacillus subtilis 168 by transformation. J. Bacteriol. 127, 817-828.

Lovett, P.S., Duvall, E.J., Bramucci, M.G., Taylor, R., 1977. Host function specified by Bacillus pumilus plasmid pPL7065. Antimicrob. Agents Chemother. 12, 435-437.

Marchler-Bauer, A., Zheng, C., Chitsaz, F., Derbyshire, M.K., Geer, L.Y., Geer, R.C., Gonzales, N.R., Gwadz, M., Hurwitz, D.I., Lanczycki, C.J., et al., 2013. CDD: conserved domains and protein three-dimensional structure. Nucleic Acids Res. 41, D348-D352.

Molina, C.A., 2010. Selection of a Bacillus pumilus Strain and Characterization of its Pathogenicity Against the Mediterranean Fruit Fly, Ceratitis capitata (Diptera: Tephritidae). In Institute of Biotechnology. Granada, University of Granada, p. 274.

Molina, C.A., Cana-Roca, J.F., Osuna, A., Vilchez, S., 2010. Selection of a Bacillus pumilus strain highly active against Ceratitis capitata (Wiedemann) larvae. Appl. Environ. Microbiol. 76, 1320-1327.

Murawska, E., Fiedoruk, K., Bideshi, D.K., Swiecicka, I., 2013. Complete genome sequence of Bacillus thuringiensis subsp. thuringiensis strain IS5056, an isolate highly toxic to Trichoplusia ni. Genome Announc. 1, e0010813.

Norman, A., Hansen, L.H., Sorensen, S.J., 2009. Conjugative plasmids: vessels of the communal gene pool. Philos. Trans. R. Soc. Lond. Ser. B Biol. Sci. 364, 2275-2289.

Ogura, M., Shimane, K., Asai, K., Ogasawara, N., Tanaka, T., 2003. Binding of response regulator DegU to the aprE promoter is inhibited by RapG, which is counteracted by extracellular PhrG in Bacillus subtilis. Mol. Microbiol. 49, 1685-1697.

Perego, M., 1997. A peptide export-import control circuit modulating bacterial development regulates protein phosphatases of the phosphorelay. Proc. Natl. Acad. Sci. U. S. A. 94, 8612-8617.

Perego, M., Hoch, J.A., 1996. Cell-cell communication regulates the effects of protein aspartate phosphatases on the phosphorelay controlling development in Bacillus subtilis. Proc. Natl. Acad. Sci. U. S. A. 93, 1549-1553.

Perego, M., Hanstein, C., Welsh, K.M., Djavakhishvili, T., Glaser, P., Hoch, J.A., 1994. Multiple protein-aspartate phosphatases provide a mechanism for the integration of diverse signals in the control of development in B. subtilis. Cell 79, 1047-1055.

Petersen, T.N., Brunak, S., von Heijne, G., Nielsen, H., 2011. SignalP 4.0: discriminating signal peptides from transmembrane regions. Nat. Methods 8, 785-786.

Reyes-Ramirez, A., Ibarra, J.E., 2008. Plasmid patterns of Bacillus thuringiensis type strains. Appl. Environ. Microbiol. 74, 125-129.

Salzberg, S.L., Delcher, A.L., Kasif, S., White, O., 1998. Microbial gene identification using interpolated Markov models. Nucleic Acids Res. 26, 544-548.

Sambrook, J., Fritsch, E.F., Maniatis, T., 1989. Molecular Cloning a Laboratory Manual. Second Edition edn. Cold Spring Harbor Laboratory Press, NY.

Seery, L., Devine, K.M., 1993. Analysis of features contributing to activity of the single-stranded origin of Bacillus plasmid pBAA1. J. Bacteriol. 175, 1988-1994. 
Sillitoe, I., Cuff, A.L., Dessailly, B.H., Dawson, N.L., Furnham, N., Lee, D., Lees, J.G., Lewis, T.E., Studer, R.A., Rentzsch, R., et al., 2013. New functional families (FunFams) in CATH to improve the mapping of conserved functional sites to 3D structures. Nucleic Acids Res. 41, D490-D498.

Singh, P.K., Ballestero-Beltran, S., Ramachandran, G., Meijer, W.J., 2010. Complete nucleotide sequence and determination of the replication region of the sporulation inhibiting plasmid p576 from Bacillus pumilus NRS576. Res. Microbiol. 161, 772-782.

Skulj, M., Okrslar, V., Jalen, S., Jevsevar, S., Slanc, P., Strukelj, B., Menart, V., 2008. Improved determination of plasmid copy number using quantitative realtime PCR for monitoring fermentation processes. Microb. Cell Factories 7, 6.

Uad, I., Toledo, F.L., Pozo, C., Silva, G.A., Gonzalez-Lopez, J., Calvo, C., 2007. Caracterización de Bacterias Productoras de Bioemulgentes Aisladas de Ambientes Marinos. In XXI Congr Nac Microbiol Sociedad Española de Microbiología. Sevilla, Spain, p. 292.

Weinberg, Z., Wang, J.X., Bogue, J., Yang, J., Corbino, K., Moy, R.H., Breaker, R.R., 2010. Comparative genomics reveals 104 candidate structured RNAs from bacteria, archaea, and their metagenomes. Genome Biol. 11, R31.
Wheeler, D.L., Church, D.M., Federhen, S., Lash, A.E., Madden, T.L., Pontius, J.U. Schuler, G.D., Schriml, L.M., Sequeira, E., Tatusova, T.A., et al., 2003. Database resources of the National Center for Biotechnology. Nucleic Acids Res. 31, 28-33.

Yang, X., McFadden, B.A., 1993. A small plasmid, pCA2.4, from the cyanobacterium Synechocystis sp. strain PCC 6803 encodes a rep protein and replicates by a rolling circle mechanism. J. Bacteriol. 175, 3981-3991.

Yoshimura, K., Yamamoto, O., Seki, T., Oshima, Y., 1983. Distribution of heterogeneous and homologous plasmids in Bacillus spp. Appl. Environ. Microbiol. 45, 1733-1740.

Zhang, Z.H., Tian, W., Liu, D.Y., Liu, Y.C., Shen, O.R., Shen, B., 2010 Characterization of a cryptic plasmid pPZZ84 from Bacillus pumilus. Plasmid 64, 200-203.

Zhong, C., Peng, D., Ye, W., Chai, L., Qi, J., Yu, Z., Ruan, L., Sun, M., 2011. Determination of plasmid copy number reveals the total plasmid DNA amount is greater than the chromosomal DNA amount in Bacillus thuringiensis YBT-1520. PLoS ONE 6, e16025. 